\title{
Recognition and Resolution of Isomeric Alkyl Anilines by Mass Spectrometry
}

\author{
Mario Benassi, ${ }^{a}$ Yuri E. Corilo, ${ }^{a}$ Diana Uria, ${ }^{\mathrm{b}}$ Rodinei Augusti, ${ }^{\mathrm{c}}$ and \\ Marcos N. Eberlin ${ }^{a}$ \\ a ThoMSon Mass Spectrometry Laboratory, Institute of Chemistry, State University of Campinas, Campinas, \\ Brazil \\ ${ }^{b}$ Federal University of Minas Gerais, Belo Horizonte, Brazil \\ ${ }^{c}$ Waters Corporation, Simonsway, United Kingdom
}

Two MS techniques have been used to recognize and resolve a representative isomeric pair of $N$-alkyl and ring-alkyl substituted anilines. The first technique (1) uses MS/MS to perform ion/molecule reactions of structurally-diagnostic fragment ions (SDFI) whereas the second (2) uses traveling wave ion mobility spectrometry (TWIMS) of the pair of protonated molecules followed by on-line collision-induced dissociation (CID), that is, MS/TWIMS-CID/MS. Isomeric $\mathrm{C}_{7} \mathrm{H}_{7} \mathrm{~N}^{+}$ions of $\mathrm{m} / \mathrm{z} 106$ ( $\mathbf{1}^{\prime}$ from 4-butylaniline and $\mathbf{2}$ from $\mathrm{N}$-butylaniline) are formed as abundant fragments by $70 \mathrm{eV}$ EI of the anilines, and found to function as suitable SDFI. Ions $\mathbf{1}^{\prime}$ and $\mathbf{2}$ display nearly identical unimolecular dissociation chemistry, but contrasting bimolecular reactivity with ethyl vinyl ether, isoprene, acrolein, and 2-methyl-1,3-dioxolane. Ion 2 forms adducts to a large extent whereas $\mathbf{1}^{\prime}$ is nearly inert towards all reactants tested. The intact protonated anilines are readily resolved and recognized by MS/TWIMS-CID/MS in a SYNAPT mass spectrometer (Waters Corporation, Manchester, UK). The protonated N-butyl aniline (the more compact isomer) displays shorter drift time and higher lability towards CID than its 4-butyl isomer. The general application of SDFI $\mathbf{1}^{\prime}$ and $\mathbf{2}$ and other homologous and analogous ions and MS/TWIMS-CID/MS for absolute recognition and resolution of isomeric families of $N$-alkyl and ring-alkyl mono-substituted anilines and analogues is discussed. (J Am Soc Mass Spectrom 2009, 20, 269-277) (C) 2009 Published by Elsevier Inc. on behalf of American Society for Mass Spectrometry

$\mathrm{I}$ somers have distinct structures and properties, but exactly the same mass. Mass spectrometry measures primarily mass; hence when dealing with intact gaseous species, MS is inherently blind for distinguishing isomers. Many MS strategies based on the correlation between structure and physicochemical properties, such as those exploring uni- or bimolecular reactivity, have therefore been developed to recognize and resolve gaseous isomeric ions [1]. Isomers sometimes display, however, very similar gaseous reactivities and still end up being indistinguishable by these approaches. Isomers have also been treated in case by case approaches and, up to now, no general MS strategy for isomer recognition and resolution is available.

We have recently proposed a MS/MS strategy for wide-ranging, absolute (noncomparative) recognition and resolution of constitutional isomers based on structurally diagnostic fragment ions (SDFI) [2]. The main SDFI requisites are that they must: (1) be a fragment ion shared by most (ideally by all) members of the isomeric family; (2)

Address reprint requests to Dr. M. N. Eberlin, Institute of Chemistry, Thomson Mass Spectrometry Laboratory, State University of CampinasUNICAMP, 13083-970 Campinas, Brazil. E-mail: eberlin@iqm.unicamp.br contain and retain the structural information of its specific isomeric precursor; (3) be stable gaseous species with relatively high barriers for structural rearrangements, and (4) display contrasting dissociations or bimolecular reactivities, or both, induced and properly rationalized in terms of their distinct structures.

Although the task is by no means easy, we have so far succeeded in finding several proper SDFI for different families of constitutional isomers. For instance, pyridinium ions function as SDFI for ortho, meta and para-substituted pyridines [2, 3], pyrimidinium ions for mono-substituted pyrimidines [4], hydroxy- and amino-benzoyl cations for isomeric acylanilines and acylphenols, nitrobenzoyl cations for acyl nitrobenzenes [5], pyrrolyl cations for isomeric mono-substituted pyrroles [6], and naphthyl acylium ions for isomeric $\alpha$ - and $\beta$-acyl naphtalenes [7].

Alkyl substituted anilines represent a family of isomers that has challenged most MS approaches for isomer recognition and resolution [8]. Their EI-MS, CI-MS(/MS) and ESI-MS(/MS) [9] are usually very similar and fail to distinguish these important constitutional isomers. Herein, we show that isomeric $\mathrm{C}_{7} \mathrm{H}_{7} \mathrm{~N}^{+}$ions of $\mathrm{m} / z 106$, usually formed to a large extent by $70 \mathrm{eV} \mathrm{EI}$, function as SDFI, and therefore
(C) 2009 Published by Elsevier Inc. on behalf of American Society for Mass Spectrometry. $1044-0305 / 09 / \$ 32.00$

doi:10.1016/j.jasms.2008.10.004
Published online October 17, 2008

Received June 27, 2008

Revised October 3, 2008

Accepted October 3, 2008 


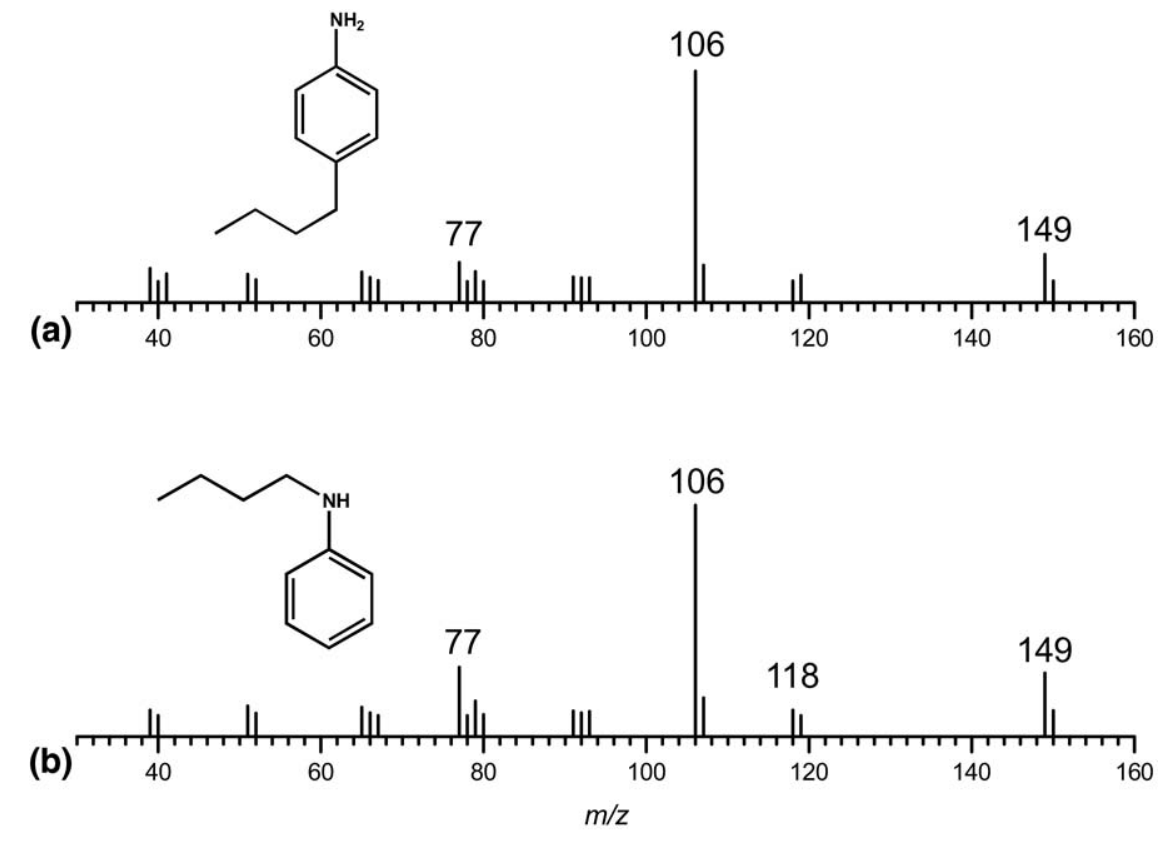

Figure 1. $70 \mathrm{eV}$ EI mass spectra of (a) 4-butylaniline and (b) N-butylaniline.

allow the recognition and resolution of $\mathrm{N}$-alkyl versus ring-alkyl mono-substituted anilines. Although protonated anilines seem to form no suitable SDFI upon CID, we also demonstrate that the intact protonated molecules can be distinguished by MS/ TWIMS-CID/MS. The generalization of these two techniques to homologue and analogue isomers is also discussed.

\section{Experimental}

The experiments with the SDFI were conducted in an Extrel (Pittsburgh, PA) pentaquadrupole mass spectrometer, which is described in detail elsewhere [10]. For the MS/MS experiments, ions were generated by $70 \mathrm{eV}$ electron ionization and selected by the first quadrupole (Q1). Ion/molecule reactions [11] with the neutral reactants ethyl vinyl ether, isoprene, acrolein, or 2-methyl-1,3-dioxolane, or CID with argon as the target gas were performed in q2. Product ion mass spectra were recorded by scanning Q5 while operating Q3 and q4 in the rf-only mode. For $\mathrm{MS}^{3}$ experiments, CID with argon of the selected (Q3) ions was performed in $\mathrm{q} 4$. The collision energies were typically near $1 \mathrm{eV}$ for ion/molecule reactions and $15 \mathrm{eV}$ for CID.

For the MS/TWIMS-CID/MS experiments, a Waters SYNAPT high definition mass spectrometer (HDMS; Waters Corporation, Manchester, UK) equipped with an ESI source was employed. More details about this hybrid mass spectrometer and its operation parameters are presented elsewhere [12]. In brief, the instrument has a hybrid quadrupole ion mobility orthogonal acceleration time-of-flight (oaTOF) geometry. Ions are transported to the mobility separation section through the quadrupole analyzer, which is operated in the resolving mode. The mobility section comprises three consecutive, gas-filled, traveling wave (TW) RF ion guides. Ions are accumulated in the TW trap and periodically released into the TW mobility cell, where they separate according to their mobility through the action of a continuous train of DC pulses. The ions exiting the TW mobility cell are then transferred to the oa-TOF analyzer for MS analysis. Ion drift times are recorded by synchronization of the oa-TOF MS acquisition with the release of ions from the TW trap to the TW mobility cell. Ions were released from the TW trap for $100 \mathrm{~ms}$

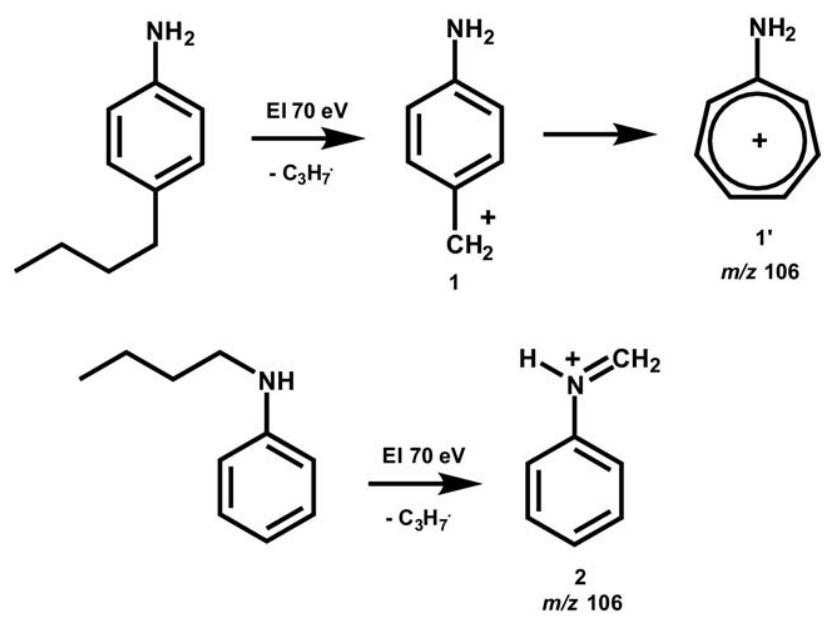

Scheme 1 

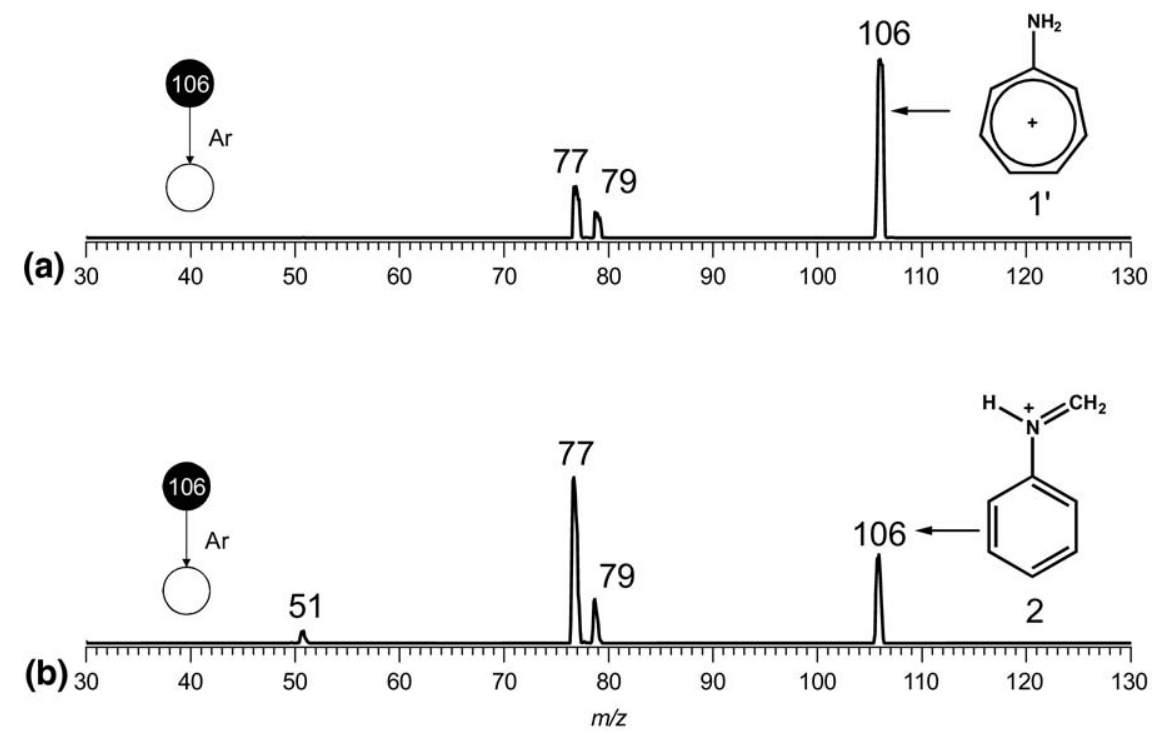

Figure 2. Product ion mass spectra for CID of the SDFI candidates $\mathbf{1}$ and $\mathbf{2}$ of $\mathrm{m} / \mathrm{z} 106$ formed via 70 eV EI of (a) 4-butylaniline and (b) $N$-butylaniline.

in every $13 \mathrm{~ms}$. Mass spectra were acquired in the positive ion mode, and the capillary voltage was $4 \mathrm{kV}$. The ion source block and nitrogen desolvation gas temperatures were set to 100 and $350{ }^{\circ} \mathrm{C}$, respectively. The TW trap and transfer cells were operated at pressures of $\sim 10^{-2}$ mbar of argon and the TW mobility cell at ca. 1 mbar of nitrogen. TWIMS was done at $300 \mathrm{~m} / \mathrm{s}$ and the DC pulse height was around $15 \mathrm{~V}$ for best separation.

\section{Results and Discussion}

As Figure 1 shows, the $70 \mathrm{eV}$ EI-MS of both isomeric 4-butylaniline and $\mathrm{N}$-butylaniline are nearly identical, offering therefore little help for isomer recognition or resolution. This similarity seems unfortunately to be a common trend for the EI-MS of isomeric alkyl anilines [9]. Both of the EI-MS of Figure 1 display, however, a major fragment ion of $\mathrm{m} / \mathrm{z}$ 106. For 4-butylaniline, the

Table 1. Products and their relative abundances for ion/molecule reactions of $\mathbf{1}^{\prime}$ and $\mathbf{2}$ with selected neutral reactants

\section{Products, $m / z$ (relative abundance)}

2-Methyl-1,3-dioxolane $\quad$ Ethyl vinyl ether
$(88 \mathrm{Da})$
$(88 \mathrm{Da})$

(72 Da)

Isoprene (68 Da)

Acrolein (56 Da)

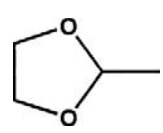

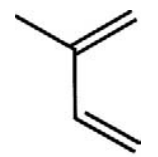

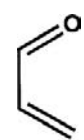

\begin{tabular}{|c|c|c|c|c|c|c|c|c|}
\hline $\begin{array}{c}\text { SDFI } \\
(\mathrm{m} / \mathrm{z} \text { 106) }\end{array}$ & Adduct & $\begin{array}{l}\text { Other } \\
\text { products }\end{array}$ & Adduct & $\begin{array}{c}\text { Other } \\
\text { products }\end{array}$ & Adduct & $\begin{array}{l}\text { Other } \\
\text { products }\end{array}$ & Adduct & $\begin{array}{l}\text { Other } \\
\text { products }\end{array}$ \\
\hline & n.d. ${ }^{a}$ & $\begin{array}{l}87{(\text { trace })^{b}}^{b}(\text { trace })^{b}\end{array}$ & n.d. & n.d. & n.d. & n.d. & n.d. & n.d. \\
\hline 2 & $150(100)$ & $\begin{array}{l}77(25)^{c} \\
87(40)^{b} \\
89(60)^{b}\end{array}$ & $\begin{array}{l}132(81) \\
178(19)\end{array}$ & $101(100)^{d}$ & $174(100)$ & n.d. & $162(100)$ & $\begin{array}{c}57(70)^{\mathrm{e}} \\
77(9)^{\mathrm{c}} \\
79(30)^{\mathrm{c}} \\
113(26)^{\mathrm{e}}\end{array}$ \\
\hline
\end{tabular}

\footnotetext{
a Not detected.
}

${ }^{\mathrm{b}}$ The ions of $\mathrm{m} / \mathrm{z} 89$ and 87 arise from proton transfer to, and hydride abstraction from, 2-methyl-1,3-dioxolane, respectively.

'The ions of $m / z 77$ and 79 are fragments of both 1 ' and 2, see Figure 2.

dSecondary product ion from ethylation of ethyl vinyl ether, see reference 15.

eThe ions of $\mathrm{m} / \mathrm{z} 57$ and 113 are protonated acrolein and the acrolein proton-bound dimer, respectively. 


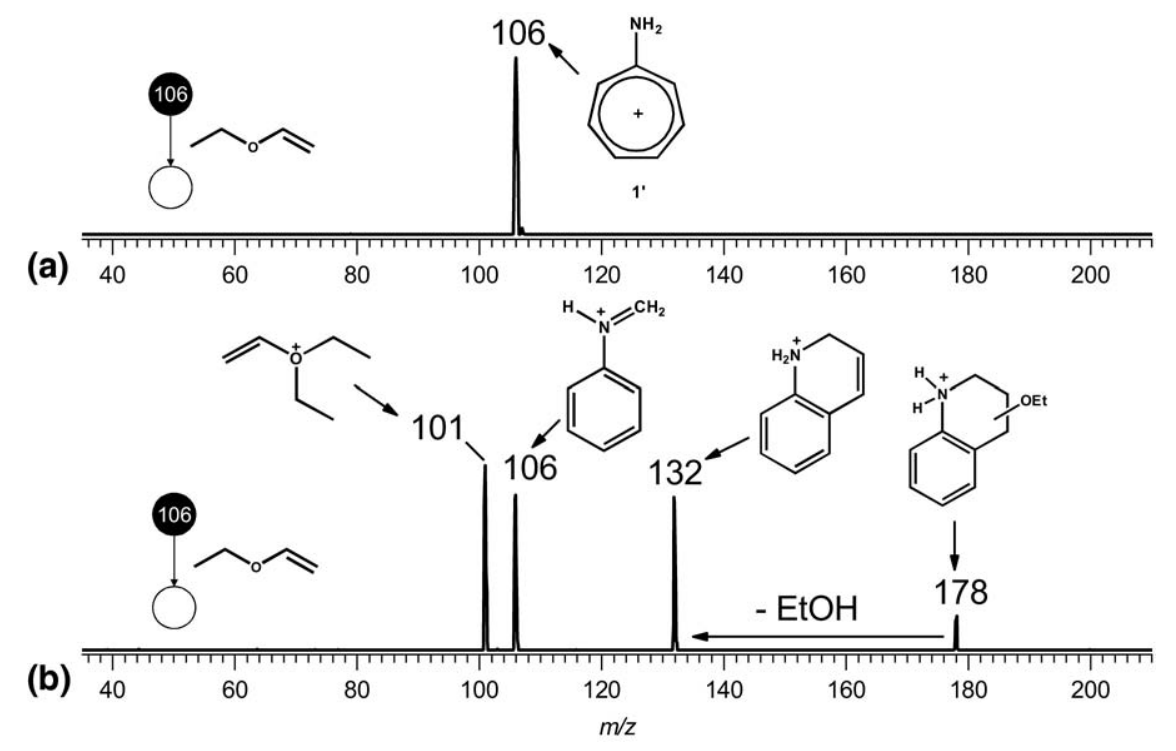

Figure 3. Product ion mass spectra for the reaction of ethyl vinyl ether with gaseous (a) $\mathbf{1}^{\prime}$ and (b) 2. The ethylated ethyl vinyl ether ion of $\mathrm{m} / \mathrm{z} 101$ is a common secondary product ion in ion/molecule reactions of ethyl vinyl ether [15].

nascent ion of $\mathrm{m} / \mathrm{z} 106$ is most likely the 4-aminobenzyl cation 1 (Scheme 1), but based on extensive investigations on the gaseous benzyl cation and the use of $70 \mathrm{eV}$ EI [13], the ion is likely to isomerize to the aminotropylium ion $\left(\mathbf{1}^{\prime}\right)$. Therefore, we assume that the quite stable, fully delocalized $\mathbf{1}^{\prime}$ is formed. If this isomerization indeed occurs, it precludes resolution, via this SDFI, between the ring-alkyl isomers having ortho, meta or para substituents. Ring versus $\mathrm{N}$-substitution recognition and resolution should be, however, straightforward since dissociative EI of the isomeric $N$-butylaniline (Figure 1) is likely to form the potentially more reactive phenylimmonium ion 2 as the nascent and stable ion of $\mathrm{m} / \mathrm{z} 106$ (Scheme 1).

Ions $\mathbf{1}^{\prime}$ and 2, owing to their high yield via $70 \mathrm{eV} \mathrm{EI}$, distinctive structures (and hence potential distinct reactivities) and expected gas-phase stabilities towards interconversion or further rearrangements, are potential candidates for SDFI for the absolute (noncomparative) MS recognition and resolution of isomeric $\mathrm{N}$-alkyl versus ring-alkyl mono-substituted anilines.

\section{Intrinsic Chemistry of Gaseous 1' and 2}

Despite their contrasting chemical structures, the SDFI candidates $\mathbf{1}^{\prime}$ and $\mathbf{2}$ of $\mathrm{m} / \mathrm{z} 106$ display very similar dissociation chemistry. Although 2 seems to be more fragile toward $15 \mathrm{eV}$ collisions with argon (Figure 2), both isomers dissociate to form a pair of major fragment ions of $\mathrm{m} / \mathrm{z} 79$ and 77 at nearly the same relative ratio. Likely, $\mathbf{1}^{\prime}$ and $\mathbf{2}$ dissociate by the loss of a neutral molecule of $\mathrm{HCN}$ (or HNC) and then $\mathrm{H}_{2}$.

Ions $\mathbf{1}^{\prime}$ and $\mathbf{2}$ are indistinguishable by CID, as just shown, but fortunately they display very contrasting bimolecular reactivities (Table 1). In ion/molecule reac- tions with selected neutrals, 2 reacts extensively to form adducts or related products, whereas $\mathbf{1}^{\prime}$ is essentially inert. As Figure $3 \mathrm{~b}$ exemplifies, 2 seems to react to a large extent with ethyl vinyl ether via polar $\left[4^{+}+2\right]$ cycloaddition [14] to form an adduct of $m / z 178[15,16]$. As a common feature of enol ethers cycloadducts [17], the cycloadduct of $\mathrm{m} / \mathrm{z} 178$ dissociates partially under the low-energy ion/molecule reaction conditions by the loss of ethanol (46 Da) to form an additional product ion of $\mathrm{m} / \mathrm{z} 132$ (Scheme 2). The intact cycloadduct of $\mathrm{m} / \mathrm{z} 178$, when isolated and subjected to low-energy CID, undergoes retrocycloaddition [18] to reform the parent reactant ion of $\mathrm{m} / \mathrm{z} 106$ (MS ${ }^{3}$ not shown). By comparison, as Figure $3 a$ illustrates, the isomeric $\mathbf{1}^{\prime}$ is nearly inert
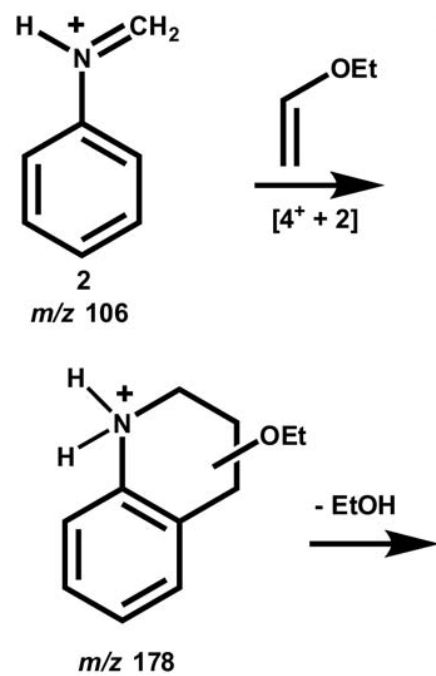

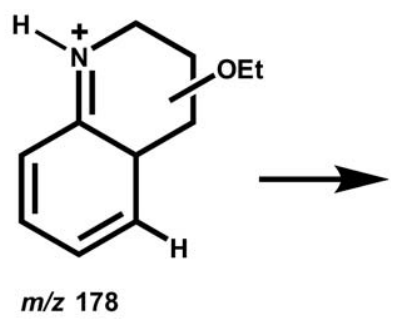

Scheme 2 
(a)
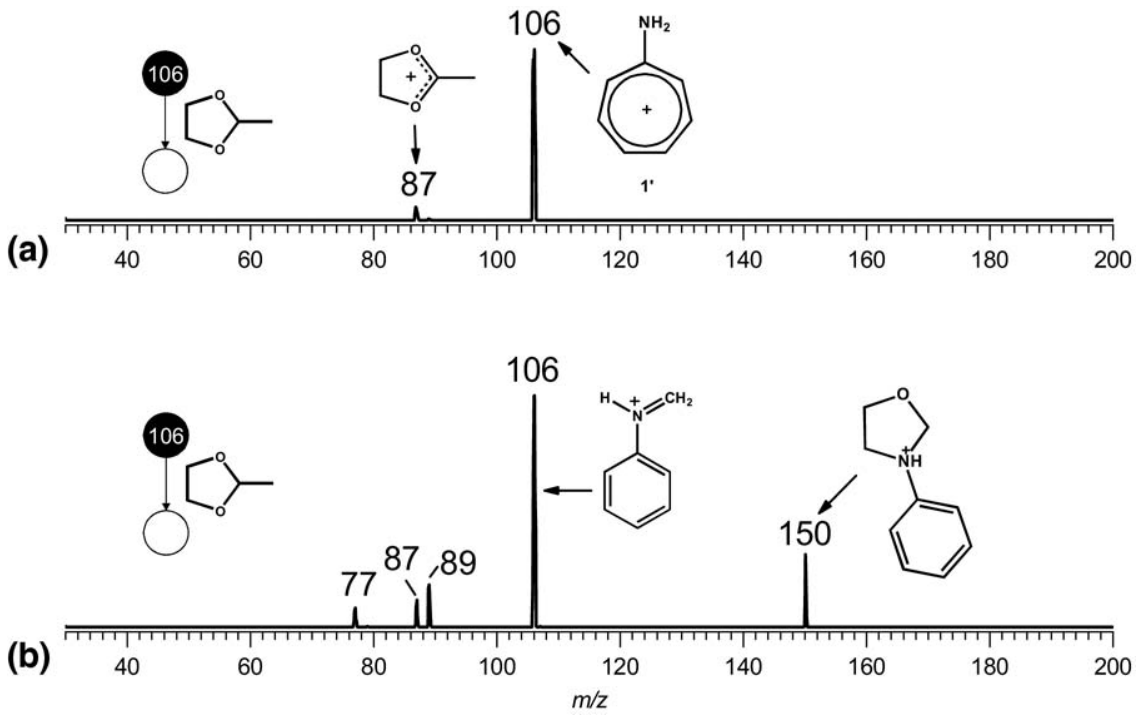

Figure 4. Product ionmass spectra for the reaction with 3-methyl-1,3-dioxolane of (a) $\mathbf{1}^{\prime}$ and (b) 2 .

towards ethyl vinyl ether, forming no detectable products. Therefore, the inertness of $\mathbf{1}^{\prime}$ and prompt bimolecular reactivity of 2 make them suitable SDFI for the general resolution of isomeric pairs of $\mathrm{N}$-alkyl and ring-alkyl mono-substituted anilines.

As previous results with analogous immonium ions anticipate, [19], $\mathbf{1}^{\prime}$ and $\mathbf{2}$ also display very contrasting reactivity in polar transacetylization [20] with 3-methyl-1,3-dioxolane. The immonium ion 2 reacts extensively to yield the expected product of $\mathrm{m} / \mathrm{z} 150$ (Figure $4 \mathrm{~b}$ and Scheme 3). As revealed by its $\mathrm{MS}^{3}$ (not shown) and summarized in Scheme 4, the CID chemistry of the product ion of $\mathrm{m} / \mathrm{z} 150$ is consistent with its proposed structure. The aromatic and fully deloca-
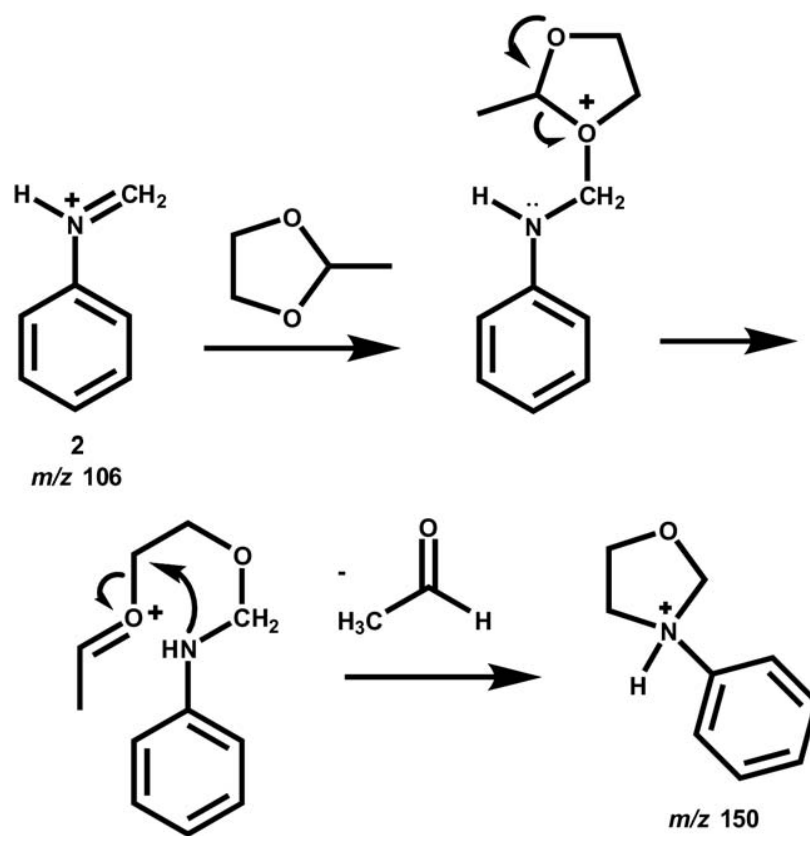

Scheme 3

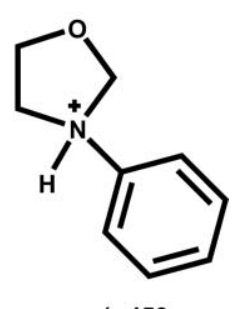

$m / z 150$ lized aminotropylium ion $\mathbf{1}^{\prime}$ is again much less reactive under the same conditions (Figure 4a). Ion $\mathbf{1}^{\prime}$ is not totally inert towards 2-methyl-1,3-dioxolane since it forms a minor hydride abstraction product of $m / z 87$.

The immonium ion 2 also reacts to large extent via polar $\left[4+2^{+}\right]$cycloaddition with isoprene and acrolein (Scheme 5) to form the product ions of $m / z 174$ and 162, respectively (Table 1). In $\mathrm{MS}^{3}$ experiments (spectra not shown), both cycloadducts were found to dissociate exclusively via retrocycloaddition to reform 2 [21]. Again, $\mathbf{1}^{\prime}$ is unreactive towards these two neutrals under the same reaction conditions (Table 1).

\section{MS/TWIMS/MS}

xIMS coupled to MS has been shown to be effective in separating and characterizing isobaric ions [22], but this

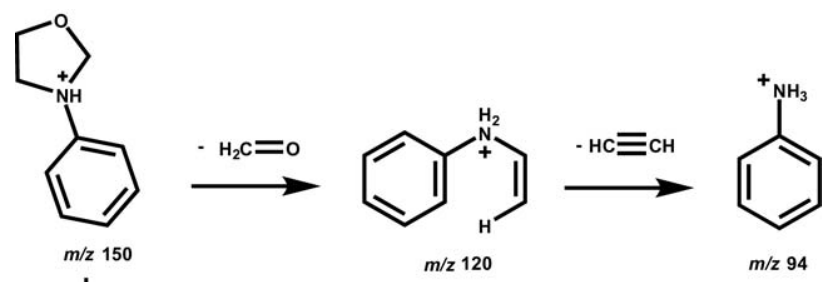<smiles>C=NC1CC1C1CC1</smiles> 


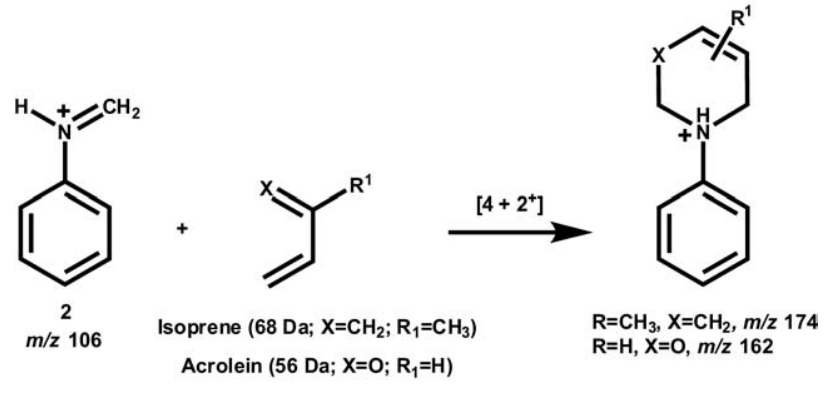

Scheme 5

technique has been less widely applied to the resolution of constitutional and enantio isomers. Nevertheless, a few successful examples have been reported, such as the resolution of enantiomers ${ }^{1 \mathrm{k}}$ and constitutional isomers of alkylated benzenes, cycloalkanes and cycloalkenes [23]. Field asymmetric IMS (FAIMS-MS) has also been used to separate and characterize isomers [24].

We therefore applied MS/TWIMS and MS/TWIMS/ MS in a SYNAPT mass spectrometer to attempt to recognize and resolve the protonated isomeric anilines generated via ESI. As Figure 5 shows, the isomeric protonated butylanilines, which were filtered previously by the Q1 quadrupole operating in the resolving mode $(m / z 150)$, are found to display considerably distinct drift times. Protonated $\mathrm{N}$-butyl aniline, which is calculated to possesses a greater mobility than protonated para-butyl aniline $\left(6.89 \times 10^{-4}\right.$ versus $6.75 \times 10^{-4}$ $\mathrm{m}^{2} \mathrm{~V}^{-1} \mathrm{~s}^{-1}$ as calculated using the trajectory method and the MOBCAL program [25], displays a shorter drift time $(2.45 \mu \mathrm{s})$ than that of protonated 4-butylaniline
(3.30 $\mu \mathrm{s})$. An ion of $m / z 94$ is also detected at $1.45 \mu \mathrm{s}$, and is recognized as protonated aniline, likely formed as a common fragment ion upon dissociation of both protonated molecules.

The protonated anilines, after being resolved in the TWIMS cell, were subsequently dissociated on-line by CID with argon (Figure 6) using this unique ability of the SYNAPT instrument. Note that the dissociation of both protonated molecules yields common fragment ions of $\mathrm{m} / \mathrm{z} 94$ (protonated aniline) and $\mathrm{m} / \mathrm{z} 57$ (the nascent $n$-butyl cation). However, the $N$-butyl isomer (Figure 6b) is found to dissociate much more readily than the 4-butyl isomer (Figure 6a) under exactly the same experimental conditions (pressure, temperature, energy, instrumental parameters). This distinct CID liability can also be used to strengthen the recognition of the isomeric alkyl anilines, and is probably associated to a lower energy barrier for the fragmentation by butane loss of protonated $N$-butylaniline versus the 4-butyl isomer dictated by the energetics of H-transfer either to $N$ or to the benzene ring. Accordingly, dissociation thresholds of $58.9 \mathrm{kcal} \mathrm{mol}^{-1}$ (N-substitution) versus $188.1 \mathrm{kcal} \mathrm{mol}^{-1}$ (para-substitution) have been predicted by BECK3LYP/6-31G(d,p) calculations (Figure 7). Note also that the combination of data from Figures 5 (MS/TWIMS/MS) and 6 (MS/TWIMS-CID/ MS) would produce a $3 \mathrm{D}$ plot from which both isomers could be more firmly recognized.

\section{Conclusions}

Chemists often face the challenge of recognizing and resolving isomers of many types, sometimes at minute

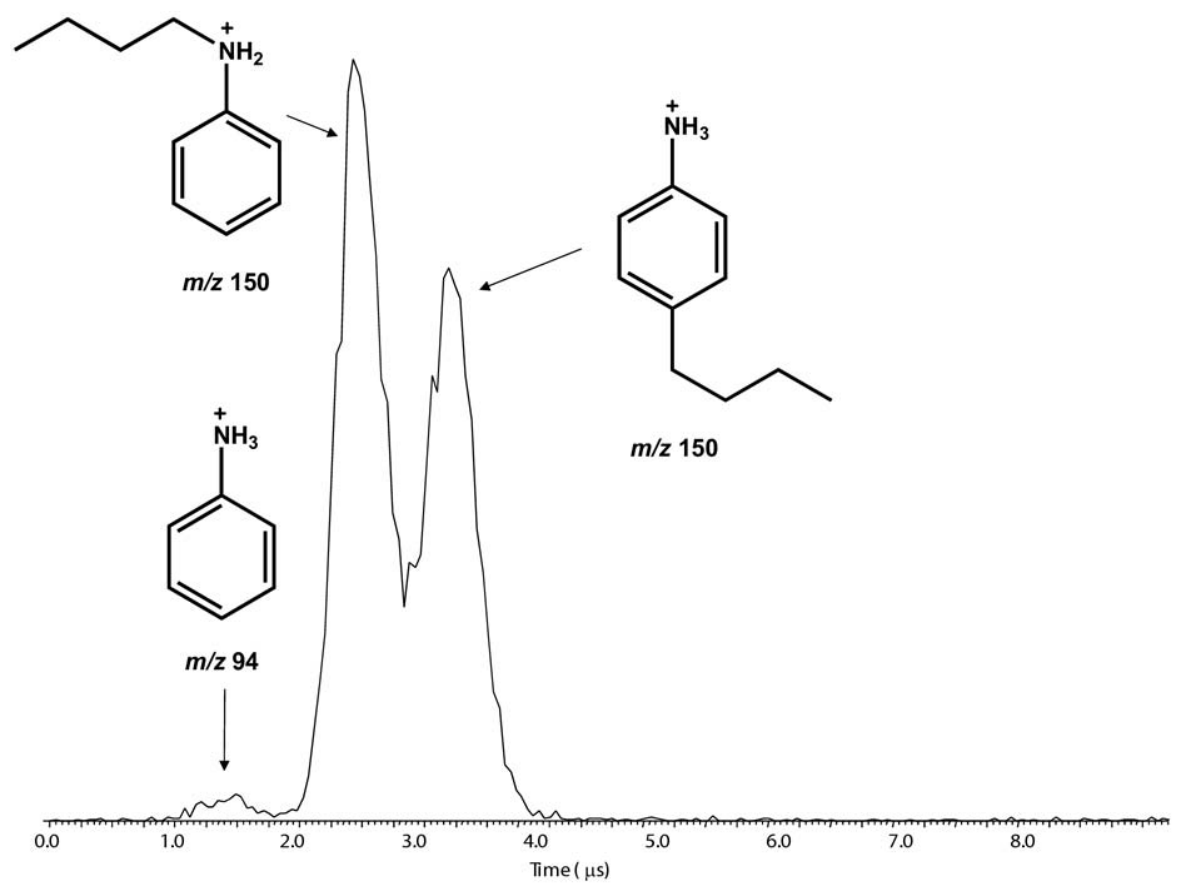

Figure 5. MS/TWIMS/MS chromatogram of a mixture of the protonated molecules of the isomeric 4-butylaniline and $N$-butylaniline of $\mathrm{m} / \mathrm{z} 106$. 


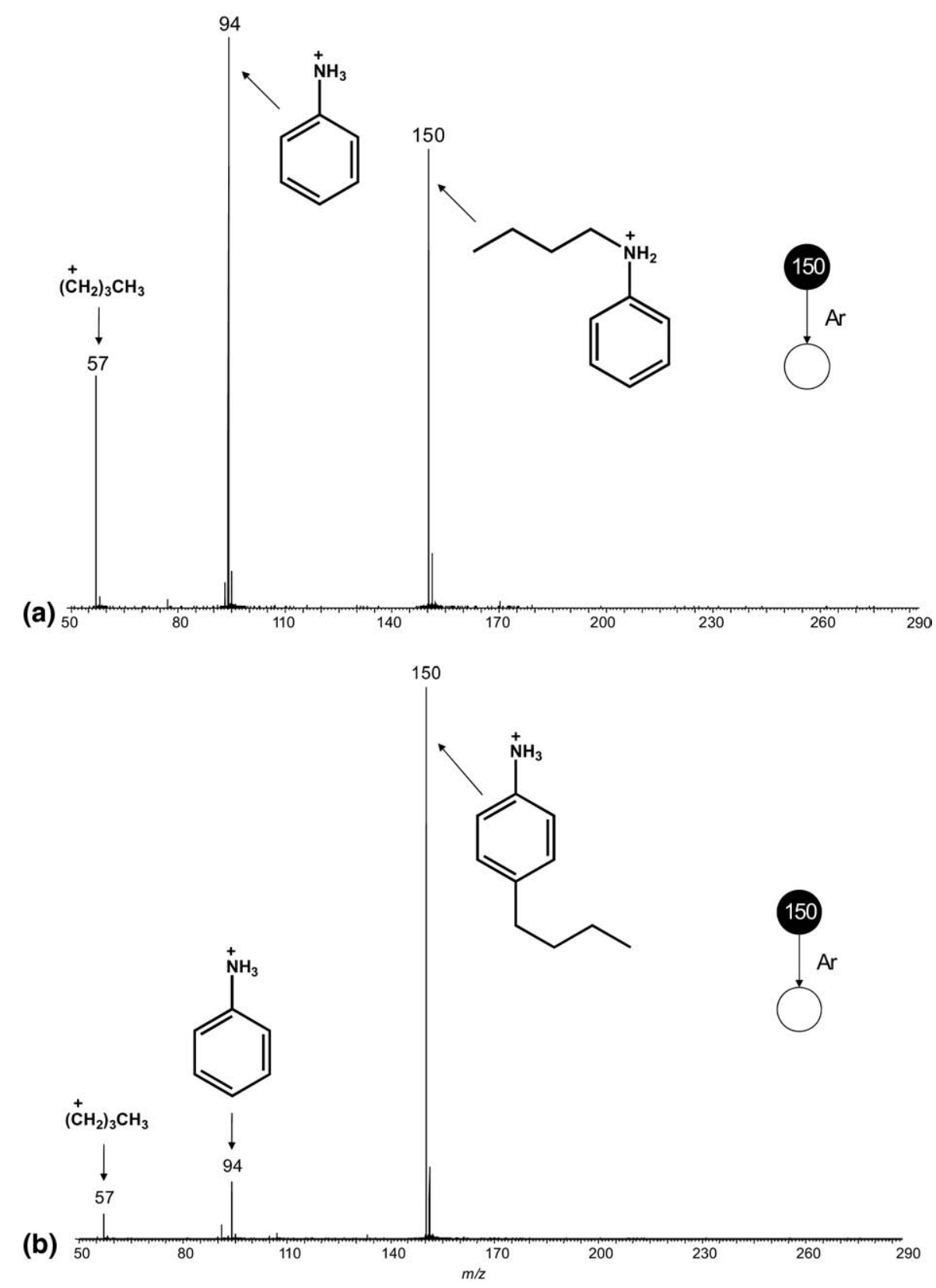

Figure 6. MS/TWIMS-CID/MS of the protonated (a) $\mathrm{N}$-butylaniline and (b) 4-butylaniline of $\mathrm{m} / \mathrm{z}$ 150. The spectra were acquired after the MS selection of the isomeric ions of $\mathrm{m} / \mathrm{z} 150$, TWIMS resolution, and on-line CID with argon.

quantities and on-line after chromatographic separation. This task is particularly frequent and challenging in synthetic organic chemistry, drug development, and natural product screening. Herein, we have used $N$-alkyl versus ring-alkyl anilines to exemplify the use of two MS methods to recognize and resolve isomers. Mono-substituted anilines normally form by EI an abundant fragment ion of $\mathrm{m} / \mathrm{z} 106$ of $\mathrm{C}_{7} \mathrm{H}_{7} \mathrm{~N}^{+}$composition, which, depending on the position of the substituent, is constituted of either the isomeric SDFI 1' or 2. These SDFI display undistinguishable CID behavior but very contrasting bimolecular reactivity. That is, 2 reacts readily to form abundant adducts and condensation products, whereas $\mathbf{1}^{\prime}$ is essentially inert.
Using these SDFI, single isomers may be recognized and many isomeric pairs or $\mathrm{N}$-substituted versus ring-substituted anilines resolved.

This strategy may be extended to other analogue and homologue classes of isomeric anilines and related compounds, since other analogue or homologue SDFI displaying contrasting reactivities are likely to be found. For instance, $\mathrm{N}, \mathrm{N}$-di-alkyl substitution could be distinguished from ring substitution using an analogue pair of immonium and aminotropylium ions (Scheme 6). Figure S1, which can be found in the electronic version of this article, provides a schematic illustration of this general MS approach. 
When dealing with protonated molecules formed by either CI or ESI, or any other atmospheric pressure ionization, MS/TWIMS/MS alone or in addition to on-line CID, MS/TWIMS-CID/MS, have been shown to be efficient MS approaches to recognize or resolve intact $\mathrm{N}$-substituted versus ring-substituted aniline isomers. Protonated N-butyl aniline was found to display a smaller cross section and to display therefore considerably shorter drift time and higher lability towards CID than the isomeric ring-butyl aniline. The generality of this trend is being investigated in our laboratory, but preliminary results show that it is likely to hold as a quite general trend of pairs for protonated isomers of $\mathrm{N}$-alkyl versus ring-alkyl substituted anilines, and analogue or homologue molecules. We are testing systematically the usefulness of this novel tandem MS approach, illustrated schematically in Scheme 6 and Figure S2, to recognize and resolve this and other classes of isomers.

\section{Acknowledgments}

The authors gratefully acknowledge the Brazilian research agencies FAPESP, CAPES, and CNPq for financial support, and Waters Micromass, UK for the authors' first and exciting HRMS SYNAPT data.
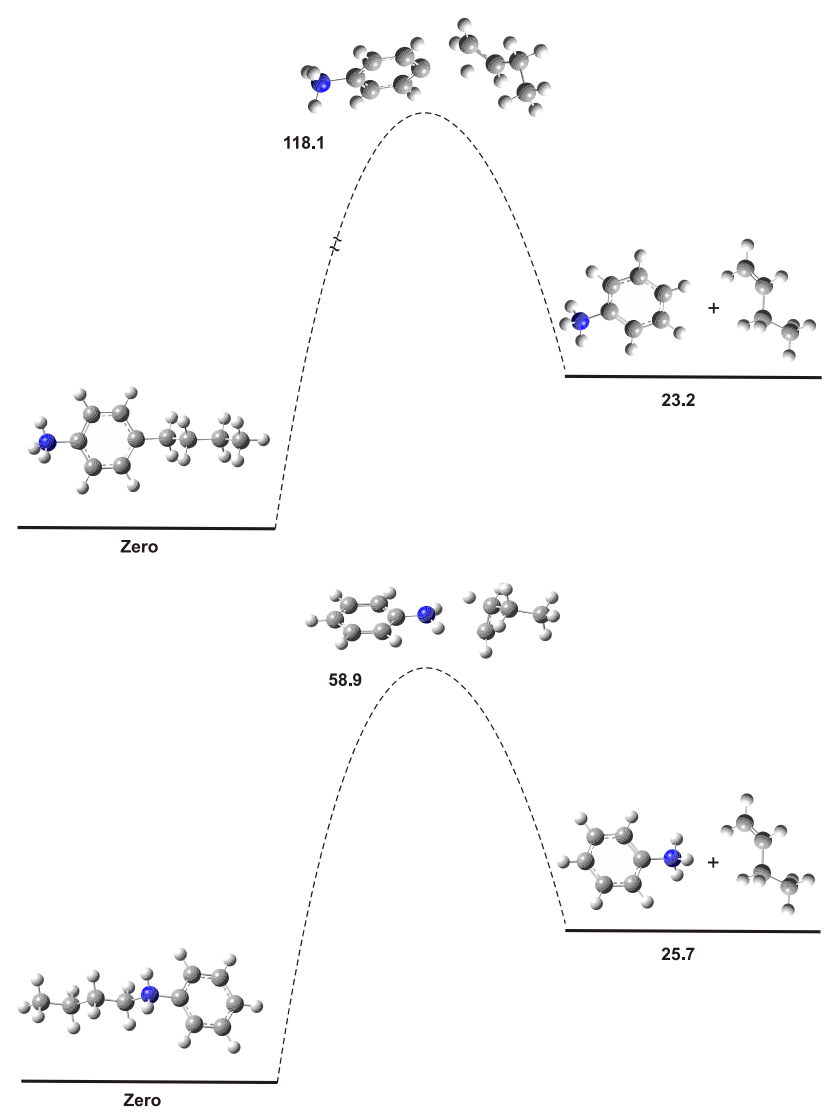

Figure 7. Dissociation thresholds for butane loss calculated at the BECK3LYP/6-31G(d,p) level for protonated para-butyl (upper) and $N$-butyl aniline. The drawings shows fully optimized structures of reactants, products, and TS. Energies are given in kcal $\mathrm{mol}^{-1}$. (a) $\overbrace{R^{2}}$

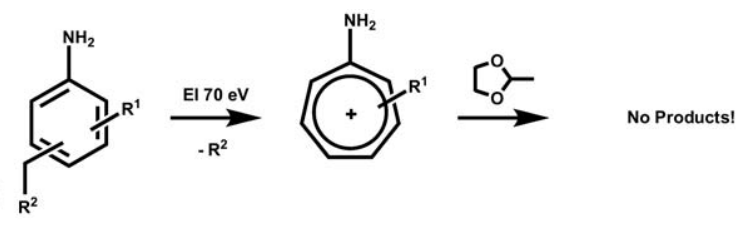

(b)<smiles>[R]CN([R])c1ccccc1</smiles>

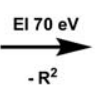<smiles>C=[N+]([14CH3])c1ccccc1</smiles>
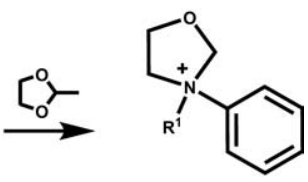

Scheme 6

\section{References}

1. (a) Tao, W. A.; Gozzo, F. C.; Cooks, R. G. Mass spectrometric quantitation of chiral drugs by the kinetic method. Anal. Chem. 2001, 73, 1692-1698. (b) Wu, L.; Meurer, E. C.; Young, B.; Yang, P.; Eberlin, M. N.; Cooks, R. G. Isomeric differentiation and quantification of alpha, beta-amino acid-containing tripeptides by the kinetic method: alkali metal-bound dimeric cluster ions. Int. I. Mass Spectrom. 2004, 231, 103-111. (c) Sorrilha, A. E. P. M.; Gozzo, F. C.; Pimpim, R. S.; Eberlin, M. N. Multiple stage pentaquadrupole mass spectrometry for generation and characterization of gas-phase ionic species. The case of the $\mathrm{PyC}_{2} \mathrm{H}_{5}{ }^{+\cdot}$ isomers. J. Am. Soc. Mass Spectrom. 1996, 7, 1126-1137. (d) Splitter, J. S.; Turecek, F., Eds.; Applications of mass spectrometry to organic stereochemistry; VCH Publishers: New York, 1994. (e) Salpin, J. Y.; Tortajada, J. Structural characterization of hexoses and pentoses using lead cationization. An electrospray ionization and tandem mass spectrometric study. J. Mass Spectrom. 2002, 37, 379-388. (f) Gross, M. L.; Lin, P. H.; Franklin, S. J. Analytical applications of ion-molecule reactionsidentification of $\mathrm{C}_{5} \mathrm{H}_{10}$ isomers by ion-cyclotron resonance spectrometry. Anal. Chem. 1972, 44, 974-978. (g) Kempen, E. C.; Brodbelt, J. Use of trimethyl borate as a chemical ionization reagent for the analysis of biologically active molecules. J. Mass Spectrom. 1997, 32, 846-854. (h) Staley, R. H.; Corderman, R. R.; Foster, M. S.; Beauchamp, J. L. Nucleophilic-attack on protonated oxiranes in gas-phase-identification of $\mathrm{C}_{2} \mathrm{H}_{5} \mathrm{O}^{+}$isomeric ions corresponding to protonated ethylene-oxide. J. Am. Chem. Soc. 1974, 96, 1260-1261. (i) Kjeldsen, F.; Haselmann, K. F.; Sorensen, E. S.; Zubarev, R. A. Distinguishing of Ile/Leu amino acid residues in the PP3 protein by (hot) electron capture dissociation in Fourier transform ion cyclotron resonance mass spectrometry. Anal. Chem. 2003, 75, 1267-1274. (j) Hsu, F. F.; Turk, J.; Gross, M. L. Structural distinction among inositol phosphate isomers using high-energy and low-energy collisional-activated dissociation tandem mass spectrometry with electrospray ionization. J. Mass Spectrom. 2003, 38, 447-457. (k) Dwivedi, P.; Wu, C.; Matz, L. M.; Clowers, B. H.; Siems, W. F.; Hill, H. H. Gas-phase chiral separations by ion mobility spectrometry. Anal. Chem. 2006, 78, 8200-8206.

2. Carvalho, M.; Gozzo, F. C.; Mendes, M. A.; Sparrapan, R.; Kascheres, C.; Eberlin, M. N. Locating the charge site in heteroaromatic cations. Chem. Eur. J. 1998, 4, 1161-1168.

3. Corilo, Y. E.; Eberlin, M. N. Recognizing $\alpha-, \beta-$, or $\gamma$-substitution in pyridines by mass spectrometry. J. Mass Spectrom. in press.

4. Moraes, L. A. B.; Sabino, A. A.; Meurer, E. C.; Eberlin, M. N. Absolute configuration assignment of ortho, meta, or para-isomers by mass spectrometry. J. Am. Soc. Mass Spectrom. 2005, 16, 431-436.

5. da Rocha, L. L.; Sparrapan, R.; Augusti, R.; Eberlin, M. N. Direct assignment of positional isomers by mass spectrometry: ortho, meta, and para-acyl and amidyl anilines and phenols and derivatives. J. Mass Spectrom. 2004, 39, 1176-1181.

6. Sparrapan, R.; Eberlin, M. N.; Augusti, R. Locating the charge site in isomeric pyrrolyl ions by Eberlin ion/molecule reactions. Rapid Commun. Mass Spectrom. 2005, 19, 1775-1778.

7. Benassi, M.; Eberlin, M. N. Extended Abstract presented at the 55th ASMS Conference on Mass Spectrometry and Allied Topics. Indianapolis, IN, June 2007.

8. Eberlin, M. N.; Augusti, D. V.; Augusti, R. In Chemistry of Anilines; Vol I. Rappoport, Z., Ed.; John Wiley and Sons: Chichester, 2007; p. 293-346.

9. Budzikiewicz, H.; Djerassi, C.; Williams, D. H. Mass Spectrometry of Organic Compounds, 1st ed.; Holden-Day: San Francisco, CA, 1967.

10. (a) Eberlin, M. N. Triple stage pentaquadrupole (QqQqQ) mass spectrometry and ion/molecule reactions. Mass Spectrom. Rev. 1997, 16, 113-144. (b) Juliano, V. F.; Gozzo, F. C.; Eberlin, M. N.; Kascheres, C. Lago, C. L. Fast multidimensional (3D and 4D) $\mathrm{MS}^{2}$ and $\mathrm{MS}^{3}$ scans in a high-transmission pentaquadrupole mass spectrometer. Anal. Chem. 1996, 68, 1328-1334.

11. Eberlin, M. N. Structurally diagnostic ion/molecule reactions: Class and functional-group identification by mass spectrometry. J. Mass Spectrom. 2006, 41, 141-156. 
12. (a) Giles, K.; Pringle, S. D.; Worthington, K. R.; Little, D.; Wildgoose, J. L.; Bateman, R. H. Rapid Commun. Mass Spectrom. 2004, 18, 2401. (b) Pringle, S. D.; Giles K.; Wildgoose, J. L.; Williams, J. P.; Slade, S. E.; Thalassinos, K.; Bateman, R. H.; Bowers, M. T.; Scrivens, J. H. An investigation of the mobility separation of some peptide and protein ions using a new hybrid quadrupole/traveling wave IMS/oa-TOF instrument. Int. J. Mass Spectrom. 2007, 261, 1-12.

13. (a) Malow, M.; Penno, M.; Weitzel, K. M. The kinetics of methyl loss from ethylbenzene and xylene ions: The tropylium versus benzylium story revisited. J. Phys. Chem. A. 2003, 107, 10625-10630; (b) Moon, J. H. Choe, J. C.; Kim, M. S. Kinetic energy release distribution in the dissociation of toluene molecular ion. The tropylium versus benzylium story continues. J. Phys. Chem. A. 2000, 104, 458-463; (c) Smith, B. J.; Hall, N. E. G2(MP2,SVP) study of the relationship between the benzyl and tropyl radicals and their cation analogues. Chem. Phys. Lett. 1997, 279, 165-171; (d) Nicolaides, A.; Radom, L. Seven-membered ring or phenyl-substituted cation-relative stabilities of the tropylium and benzyl cations and their silicon analogs. J. Am. Chem. Soc. 1994, 116, 9769-9770; (d) Cone, C.; Dewar, M. J. S.; Landman, D. Gaseous ions. 1. MINDO-3 study of rearrangement of benzyl cation to tropylium. J. Am. Chem. Soc. 1977, 99, 372-376; (e) de Koster, C. G.; van Houte, J. J.; van Thuiil, J. Gas phase substitution reactions by radical cations. Part. 3. Methylene transfer of the $\mathrm{C}-\mathrm{C}$ ring-opened oxirane radical cation to pyrazole and imidazole. Int. J. Mass Spectrom. Ion Processes. 1994, 134, 1-10; (f) Speranza, M. Gas-phase reactivity of 5-membered heteroaromatics toward electrophiles, an experimental check on theoretical predictions. Pure Appl. Chem. 1991, 63, 243-254.

14. Eberlin, M. N. Gas-phase polar cycloadditions. Int. J. Mass Spectrom. 2004, 235, 263-278.

15. Meurer, E. C.; Eberlin, M. N. Gas-phase polar $\left[4^{+}+2\right]$ cycloaddition of cationic 2-azabutadienes with enol ethers. Int. J. Mass Spectrom. 2001, 210, 469-482.

16. Meurer, E. C.; Sparrapan, R.; Eberlin, M. N. Gas-phase polar $\left[4^{+}+2\right]$ cycloaddition with ethyl vinyl ether: A structurally diagnostic ion- molecule reaction for 2-azabutadienyl cations. J. Mass Spectrom. 2003, 38, 1075-1080.

17. Augusti, R.; Gozzo, F. C.; Moraes, L. A. B.; Sparrapan, R.; Eberlin, M. N. The simplest azabutadienes in their N-protonated forms. Generation, stability, and cycloaddition-reactivity in the gas phase. J. Org. Chem. 1998, 63, 4889-4897.

18. Eberlin, M. N.; Cooks, R. G. Polar $\left[4+2^{+}\right]$Diels-Alder cycloadditions of acylium ions in the gas phase. J. Am. Chem. Soc. 1993, 115, 9226-9233.

19. Eberlin, M. N.; Morgon, N. H.; Yang, S. S.; Shay, B. J.; Cooks, R. G. Polar $\left[4+2^{+}\right]$Diels-Alder cycloaddition to nitrilium and immonium ions in the gas-phase-applications of multiple stage mass-spectrometry in a pentaquadrupole instrument. J. Am. Soc. Mass Spectrom. 1995, 6, 1-10.

20. Cooks, R. G.; Chen, H.; Eberlin, M. N.; Zheng, X.; Tao, W. A. Polar acetylization and transacetylization in the gas phase: The Eberlin reaction. Chem. Rev. 2006, 106, 188-211.

21. Meurer, E. C.; Eberlin, M. N. Mono and double polar $\left[4+2^{+}\right]$ Diels-Alder cycloaddition of acylium ions with O-heterodienes. J. Mass Spectrom. 2002, 37, 146-154.

22. Barnes, C. A. S.; Hilderbrand, A. E.; Valentine, S. J.; Clemmer, D. E. Resolving isomeric peptide mixtures: A combined HPLC/ion mobilityTOFMS analysis of a 4000-component combinatorial library. Anal. Chem. 2002, 74, 26-36.

23. (a) Borsdorf, H.; Nazarov, E. G.; Eiceman, G. A. Atmospheric pressure chemical ionization studies of non-polar isomeric hydrocarbons using ion mobility spectrometry and mass spectrometry with different ionization techniques. J. Am. Soc. Mass Spectrom. 2002, 13, 1078-1087. (b) Borsdorf, H.; Rudolph, M. Gas-phase ion mobility studies of constitutional isomeric hydrocarbons using different ionization techniques. Int. J. Mass Spectrom. 2001, 208, 67-72.

24. Kolakowski, B. M.; Mester, Z. Review of applications of high-field asymmetric waveform ion mobility spectrometry (FAIMS) and differential mobility spectrometry (DMS). Analyst. 2007, 132, 842-864.

25. Mesleh, M. F.; Hunter, J. M.; Shvartsburg, A. A.; Schatz, G. C.; Jarrold, M. F. Structural information from ion mobility measurements: Effects of the long-range potential. J. Phys. Chem. 1996, 100, 16082-16086. 